\title{
Limited Stage Small Cell Bladder Cancer: Outcomes of a Contemporary Cohort
}

\author{
Claud M. Grigg*, Danielle Boselli, Chad Livasy, James Symanowski, Derek R. McHaffie, \\ Stephen Riggs, Peter E. Clark, Hamza Beano, Derek Raghavan and Earle F. Burgess \\ Levine Cancer Institute, Atrium Health, Charlotte, NC, USA
}

Received 14 November 2019

Accepted 27 February 2020

\begin{abstract}
.
BACKGROUND: Limited stage small cell bladder cancer is curable with multi-modality therapy using external beam radiotherapy or radical cystectomy. The optimal management strategy for this rare disease is still debated, yet few case series have described patients treated after 2010.

OBJECTIVE: To analyze outcomes from a contemporary cohort of patients undergoing definitive treatment.

METHODS: Patients diagnosed with small cell bladder cancer after January 1, 2010 were identified from an institutional database. Clinical histories were collected by chart review. Survival outcomes were analyzed in patients who received curative-intent therapy consisting of bladder radiotherapy or cystectomy.

RESULTS: Thirty patients with limited stage disease that received definitive therapy were identified. Seventeen patients received primary radiotherapy, and thirteen underwent cystectomy. Median age was 70 years. Median follow up was 39.6 months (range 7.2-95.8). The median overall survival of patients undergoing radiotherapy or cystectomy were 36.8 and 30.6 months, respectively (hazard ratio $0.99,95 \%$ confidence interval $0.35-2.85$ ). The median metastasis free survival for patients receiving radiotherapy was not reached, and 18.9 months in the cystectomy group (hazard ratio $0.94,95 \%$ confidence interval $0.34-2.61)$. The most common sites of relapse were lymph node $(n=6)$ and bone $(n=5)$. Brain metastases were less common $(n=3)$.

CONCLUSIONS: Patients receiving cystectomy or radiotherapy had similar outcomes in this contemporary series, but definitive comparisons are limited by the cohort size and high censoring rate (53\%). Survival in our cohort is improved compared with older reports, though outcomes remain poor, reiterating the need for better therapeutic options.
\end{abstract}

Keywords: Bladder cancer, radiotherapy, chemotherapy, cystectomy, small cell carcinoma

\section{INTRODUCTION}

Small cell bladder carcinoma (SCBC) is a rare, aggressive type of bladder cancer which lacks large prospective studies. Patients often present with advanced disease, and prognosis is driven by stage (limited stage [LS] - tumor confined to the bladder and/or pelvic lymph nodes or extensive stage [ES] - tumor metastatic to non-regional lymph node

\footnotetext{
*Correspondence to: Claud M. Grigg, MD, Levine Cancer Institute, Atrium Health, 1021, Morehead Medical Drive, Charlotte, NC, 28204, USA. Tel.: +1 9804429600; Fax: +1 9804429707; E-mail: claud.grigg@atriumhealth.org.
}

region or organ) [1]. Optimal management of localized SCBC includes platinum-based chemotherapy and either radical cystectomy (RC) or external beam radiotherapy (EBRT). No evidence currently defines which local therapy is best or how to sequence with chemotherapy. Current practice patterns have been used for over three decades, and whether advances in supportive oncology or improvements in surgical or radiotherapy technique have improved outcomes in this disease is unknown.

Tobacco use increases the risk for SCBC, and patients typically present after the 6th decade of life [1]. Thus significant comorbidity often limits eligibil- 
ity for cystectomy, with observed rates of cystectomy in SEER and NCDB ranging from 19-31\% and 16\% in those over age 75 [2-4]. Combined modality therapy with maximal TURBT, EBRT, and chemotherapy may be better tolerated and more widely available, though is only utilized in about $25 \%$ of patients [3, 4]. Recommendations for the treatment of LS-SCBC are mostly extrapolated from the urothelial carcinoma (UC) and small cell lung cancer (SCLC) literature. Small institutional series support these guidelines, though many of those patients were treated before the year 2000 [5-9]. Here, we present a contemporary experience of patients with LS-SCBC who received definitive therapy at our institution.

\section{METHODS}

The Levine Cancer Institute (LCI) is an academic hybrid cancer center serving Atrium Health, a large health care network centered in Charlotte, $\mathrm{NC}$, which incorporates 45 hospitals and treats more than 17,000 new cancer cases per year. Subjects for this study were identified from an institutional review board approved tumor database (IRB approval number: Pro00023417). All diagnoses were confirmed by a pathologist at LCI specializing in genitourinary cancer using conventional histological and immunohistochemical techniques. Transurethral resection of bladder tumor (TURBT) or cystectomy specimens containing SCBC between January 1, 2010 and December 31, 2017 were identified. Pure and mixed SCBC tumor histologies were included. Histologic requirements for the diagnosis of SCBC were based on World Health Organization criteria for small cell pathology [10].

Demographic and clinical histories were obtained by chart and death record review. Patients with documented ES-SCBC at or within 30 days of diagnosis were excluded. LS-SCBC was defined as stage I-III bladder cancer, analogous to the SCLC staging system [11]. Patients with LS-SCBC received either definitive radiotherapy or radical surgical resection. Most patients also received multi-agent, platinumbased chemotherapy as part of primary therapy.

Baseline patient and disease characteristics were summarized descriptively. Overall (OS) and metastasis-free survival (MFS) were analyzed. OS and MFS were measured from the date of histologic SCBC diagnosis to death and to death or metastatic recurrence, respectively. The date of metastatic recurrence was defined as any clinical, radiographic, or pathologic documentation of extravesicular recurrence, whichever occurred first. Patients not treated with curative intent were excluded from survival analyses. For subjects who did not experience events of interest, MFS and OS were censored at last known alive date, with a final data abstraction performed on September 1, 2018. MFS and OS rates were estimated using the Kaplan-Meier method and compared between cohorts with the log-rank test; Cox proportional hazard models were used to estimate the effect of treatment modality or receipt of chemotherapy with univariate models and multivariate models when adjusting for age or stage at SCBC diagnosis. Statistical analyses were performed using SAS (version 9.4, SAS Institute, Cary, NC, U.S.A.).

\section{RESULTS}

\section{Baseline characteristics}

Forty one patients with SCBC pathology and limited stage disease were identified, which represented $1.5 \%(41 / 2753)$ of all bladder cancer diagnoses recorded within the institutional tumor registry during the study time period. Of these 41 patients, seven did not undergo documented treatment with curative intent and four were lost to follow up. The reasons for omission of radiation or surgery included: advanced age plus comorbidity $(n=5)$, rapid progression to metastatic disease $(n=1)$, and refusal to undergo surgery or radiation $(n=1)$.

Thirty patients who underwent definitive local therapy with either RC or EBRT were analyzed. Characteristics of this cohort are presented in Table 1. This population was predominantly elderly (median age 70 years; range 52-88), Caucasian (90.0\%), and male $(80.0 \%)$. Most of the patients were current (within 30 days of diagnosis) or former smokers; six $(20.0 \%)$ were never smokers. Eight (26.7\%) patients had a prior diagnosis of non-muscle invasive urothelial carcinoma. Four patients had a prior diagnosis of prostate adenocarcinoma, two of whom had undergone prostate radiotherapy approximately 5 and 13 years before their SCBC diagnosis.

Detailed pathology assessment was undertaken for all patients by our genitourinary tumor pathologist. Pure SCBC was described in $8(26.7 \%)$ cases, while $22(73.3 \%)$ harbored one or more additional histologic components including UC $(n=19)$, large cell neuroendocrine carcinoma $(n=2)$, sarcomatoid carcinoma $(n=2)$, and adenocarcinoma $(n=1)$. 
Table 1

Baseline characteristics of patients with LS-SCBC receiving definitive treatment

\begin{tabular}{|c|c|c|}
\hline & RC cohort $(n=13)$ & EBRT cohort $(n=17)$ \\
\hline Characteristic & Median [Range] & Median [Range] \\
\hline$\overline{\text { Age at diagnosis (years) }}$ & $66[55,80]$ & $76[52,88]$ \\
\hline \multirow[t]{2}{*}{ Body mass index $\left(\mathrm{kg} / \mathrm{m}^{2}\right)$} & $27[22-36]$ & $30[20-45]$ \\
\hline & Frequency $(\%)$ & Frequency $(\%)$ \\
\hline \multicolumn{3}{|l|}{ Gender } \\
\hline Male & $11(85)$ & $13(76)$ \\
\hline Female & $2(15)$ & $4(24)$ \\
\hline \multicolumn{3}{|l|}{ Race } \\
\hline Caucasian & $13(100)$ & $14(82)$ \\
\hline Black & $0(0)$ & $2(12)$ \\
\hline Other/Unknown & $0(0)$ & $1(6)$ \\
\hline \multicolumn{3}{|l|}{ Smoking status } \\
\hline Current smoker & $2(15)$ & $2(12)$ \\
\hline Former smoker & $6(46)$ & $13(76)$ \\
\hline Never smoker & $4(31)$ & $2(12)$ \\
\hline Unknown & $1(8)$ & $0(0)$ \\
\hline \multicolumn{3}{|l|}{ Prior urothelial carcinoma } \\
\hline No & $10(77)$ & $12(71)$ \\
\hline Yes & $3(23)$ & $5(29)$ \\
\hline \multicolumn{3}{|l|}{ Tumor histology } \\
\hline Pure small cell carcinoma & $3(23)$ & $5(29)$ \\
\hline Mixed small cell carcinoma $+\mathrm{UC}$ & $8(62)$ & $10(59)$ \\
\hline Mixed small cell carcinoma + other & $2(15)$ & $2(12)$ \\
\hline \multicolumn{3}{|l|}{ Clinical tumor stage } \\
\hline $\mathrm{T} 2$ & $12(92)$ & $14(82)$ \\
\hline $\mathrm{T} 3+$ & $1(8)$ & $3(18)$ \\
\hline \multicolumn{3}{|l|}{ Clinical node stage } \\
\hline No & $12(92)$ & $16(94)$ \\
\hline N1 & $1(8)$ & $0(0)$ \\
\hline $\mathrm{N} 2+$ & $0(0)$ & $1(6)$ \\
\hline
\end{tabular}

\section{Definitive local management}

Curative-intent local therapy with either RC or EBRT was pursued in 30 patients with limited-stage disease, including RC in 13 cases and EBRT in 17 cases. All patients who underwent RC had negative surgical margins. Eleven of the RC patients $(85 \%)$ received perioperative chemotherapy including eight patients who received neoadjuvant chemotherapy only, two patients received adjuvant chemotherapy only, and one received both (Table 2). All patients received 3-5 cycles of a platinum agent plus etoposide except one who received platinum plus gemcitabine prior to the identification of SCBC histology at cystectomy. Three patients were found to have nodal metastasis at cystectomy ( $\mathrm{pN} 1: n=2$; pN2: $n=1$ ). Five patients demonstrated a pathologic complete response (pCR, ypT0) or only residual noninvasive carcinoma (ypTa or ypTis) at cystectomy. None of the six tumors with ypT0-T2 disease had any residual small cell component, while all ypT3+ tumors harbored residual small cell histology.

Seventeen patients underwent TURBT followed by EBRT without cystectomy. The cited reasons for choosing EBRT instead of RC were: patient preference $(n=9)$, comorbidities precluding surgery $(n=5)$, and advanced disease deemed non-operable $(n=3)$. The median radiation dose used was $61.2 \mathrm{~Gy}$ (range 48.6-66.6 Gy) in 34 fractions (range 22-37 fractions) at $1.8 \mathrm{~Gy}$ per fraction (range 1.8-2.25 Gy per fraction). The treatment volume included the pelvic nodes for 13 patients $(76.4 \%)$ to a median dose of $45 \mathrm{~Gy}$ (range 39.6-45 Gy). Two patients $(11.7 \%)$ failed to complete radiotherapy as prescribed (noncompliance; cardiac event). $88 \%$ of patients received chemotherapy for local disease. Most of these patients received platinum-based chemotherapy (cisplatin + etoposide $[n=4]$, carboplatin + etoposide $[n=8]$, carboplatin $[n=1]$, gemcitabine $[n=1], 5-$ $\mathrm{FU}+$ mitomycin $\mathrm{C}[n=1])$. All patients receiving platinum-based doublets underwent 3 or 4 cycles. Sequential $(n=7)$ and concurrent $(n=8)$ administration of chemotherapy were equally utilized. One patient who completed six cycles of neoadjuvant platinum chemotherapy had an isolated pelvic bone metastasis at restaging but still proceeded with chemoradiation encompassing the bone lesion. Twelve (92\%) of thirteen patients who underwent 
Table 2

Treatment characteristics of patients receiving definitive treatment

\begin{tabular}{|c|c|}
\hline Characteristic & Median [Range] \\
\hline \multicolumn{2}{|c|}{ Surgical Cohort $(n=13)$} \\
\hline \multirow[t]{2}{*}{ Lymph nodes removed } & 9 [0-19] \\
\hline & Frequency $(\%)$ \\
\hline \multicolumn{2}{|l|}{$\overline{\text { Pathologic tumor stage }}$} \\
\hline T0 & $3(23.1)$ \\
\hline $\mathrm{Ta}$ & $1(7.7)$ \\
\hline Tis & $1(7.7)$ \\
\hline $\mathrm{T} 1$ & $0(0)$ \\
\hline $\mathrm{T} 2$ & $4(30.8)$ \\
\hline $\mathrm{T} 3$ & $3(23.1)$ \\
\hline $\mathrm{T} 4$ & $1(7.7)$ \\
\hline \multicolumn{2}{|l|}{ Pathologic node stage } \\
\hline No & $9(69.2)$ \\
\hline N1 & $2(15.4)$ \\
\hline $\mathrm{N} 2$ & $1(7.7)$ \\
\hline $\mathrm{Nx}$ & $1(7.7)$ \\
\hline \multicolumn{2}{|c|}{ Neoadjuvant chemotherapy regimen } \\
\hline Carboplatin/Etoposide & $2(15.4)$ \\
\hline Cisplatin/Etoposide & $6(46.2)$ \\
\hline Cisplatin/Gemcitabine & $1(7.7)$ \\
\hline None & $4(30.8)$ \\
\hline \multicolumn{2}{|c|}{ Radiation Cohort $(n=17)$} \\
\hline & Median [Range] \\
\hline \multirow[t]{2}{*}{ Composite radiation dose $(G y)$} & $61.2[48.6,66.6]$ \\
\hline & Frequency $(\%)$ \\
\hline \multicolumn{2}{|l|}{ Chemotherapy Sequence } \\
\hline Concurrent & $8(53.3)$ \\
\hline Sequential & $7(46.7)$ \\
\hline \multicolumn{2}{|l|}{ Chemotherapy Regimen } \\
\hline Carboplatin/Etoposide & $8(47.1)$ \\
\hline Cisplatin/Etoposide & $4(23.5)$ \\
\hline Other & $3(17.6)$ \\
\hline None & $2(11.8)$ \\
\hline
\end{tabular}

cystoscopic surveillance within the first 6 months had no residual tumor. One patient with residual viable SCBC was diagnosed with metastatic disease soon after cystoscopic confirmation of disease.

\section{Outcomes after definitive therapy}

Overall and metastasis-free survival were analyzed in thirty patients receiving definitive treatment. Median follow-up of censored patients in the survival cohort was 39.6 months (7.2 - 95.8 months). Fourteen $(53 \%$ censored) deaths occurred, and median OS was 36.8 months (95\% confidence interval [CI] 17.6 - non-estimable [NE]). One, two, and three-year OS landmark rates were $86 \%, 65 \%$, and $51 \%$, respectively. Fifteen patients developed distant metastasis or died (50\% censored), and the median MFS was 18.9 months (95\% CI 11.5 - NE). One, two, and threeyear MFS landmark rates were $69 \%, 48 \%$, and $48 \%$, respectively.
Although a numerical difference in median OS was observed between patients treated with EBRT (median OS 36.8 months, 95\% CI 13.7 - NE) and RC (median 30.6 months, 95\% CI 15.6 - NE), the overall survival curves in these two cohorts were similar (HR 0.99, 95\% CI $0.35-2.85$, log-rank $p=0.991$, Fig. 1A). Similarly, median MFS in the EBRT cohort was not reached (95\% CI $11.5-\mathrm{NE}$ ), whereas median MFS in those undergoing RC was 18.9 months (95\% CI 10.4 - NE) (EBRT vs RC: HR 0.94, 95\% CI $0.34-2.61$, log-rank $p=0.908$, Fig. 1B). After adjustment for age or stage at diagnosis, OS and MFS results for RC vs EBRT treatment group comparisons were similar to the previously described unadjusted results.

The use of multimodality treatment that included chemotherapy was associated with improved MFS (HR 0.26, 95\% CI $0.08-0.84$, log-rank $p=0.015$ ) in the overall cohort. A trend towards OS benefit was observed (HR 0.45, 95\% CI 0.14-1.44, log-rank $p=0.165$ ) (Fig. 1C-D). The 3-year OS rate was $60 \%$ after chemotherapy versus $20 \%$ without chemotherapy, and the 3 -year MFS rate was $54 \%$ with versus $20 \%$ without chemotherapy. Of the five patients who experienced tumor downstaging to ypT0, ypTis, or ypTa following neoadjuvant chemotherapy, one patient died 17.6 months after diagnosis without evidence of cancer recurrence. The four remaining patients were alive without recurrence at follow up ranging from 38.9 to 68.8 months.

Metastatic relapse occurred in five patients after $\mathrm{RC}$ and six patients after EBRT. The most common sites of relapse were lymph node $(n=6)$ and bone $(n=5)$, followed by liver $(n=3)$, lung $(n=3)$, spleen $(n=1)$, and brain $(n=1)$. Two additional patients developed subsequent brain metastasis as a late complication of metastatic disease. No patients received prophylactic cranial irradiation (PCI). In the EBRT cohort, metachronous bladder-only recurrence was identified in two (11.8\%) patients. In both cases, histology was high grade urothelial carcinoma with papillary features (without a small cell component) and stage was Ta $(n=1)$ and T1 $(n=1)$. Complete responses were observed with intravesicular BCG therapy in both cases.

\section{DISCUSSION}

In this contemporary series of patients with LSSCBC treated at our center, $41 \%$ of patients were treated with EBRT, and their survival outcomes 

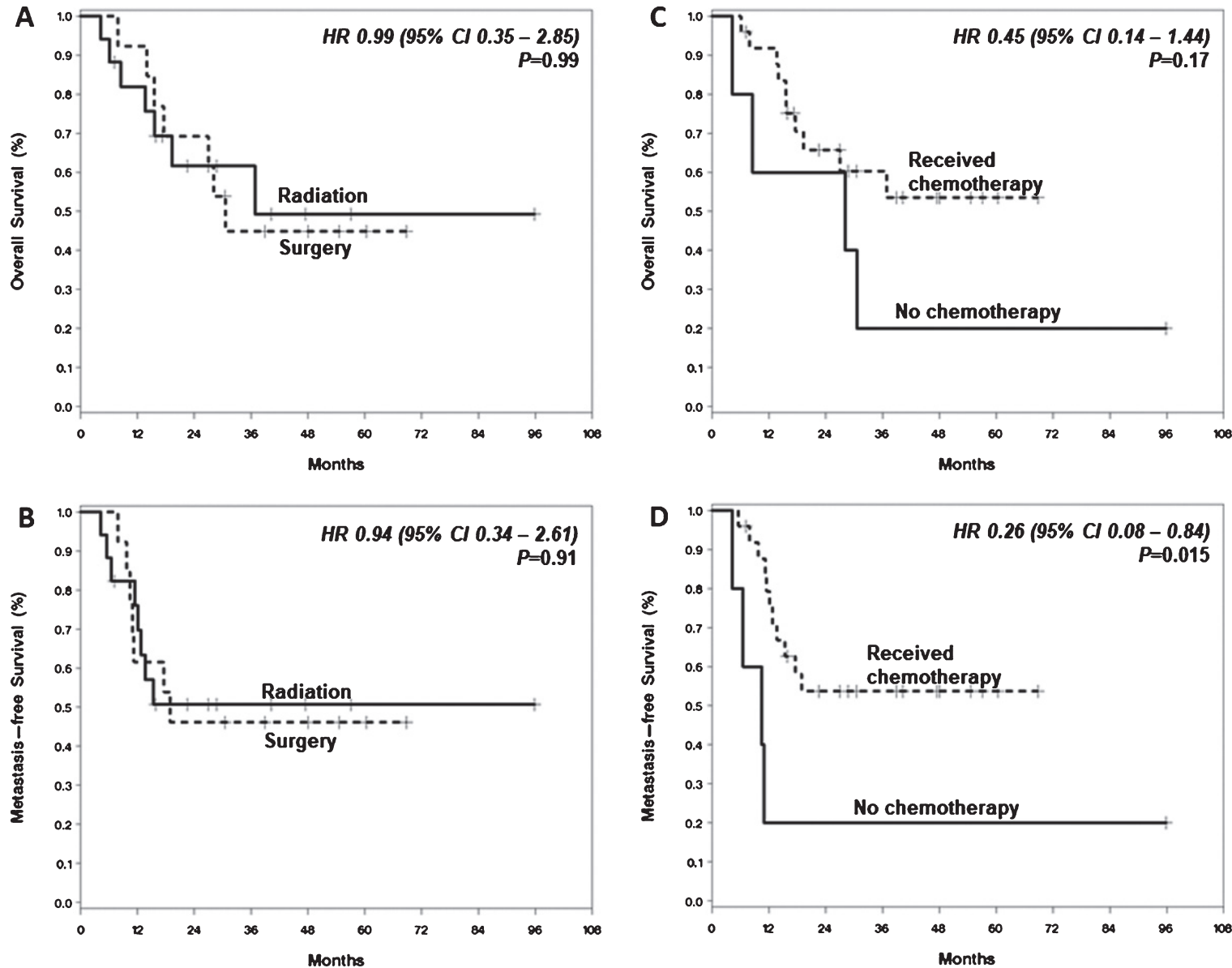

Fig. 1. Survival Curves According to Treatment Type. (A) Overall survival, RC vs EBRT. (B) Metastasis free survival, RC vs EBRT. (C) Overall survival, received any chemotherapy vs none. (D) Metastasis free survival, chemotherapy vs none. $P$ value based on the omnibus log-rank test.

appear similar to those who underwent RC (Fig. 1A) after controlling for age and stage. Other uncontrolled factors may also influence treatment decisions and outcome and would be expected to favor the surgically treated cohort, yet outcomes were not different. For example, nearly half of patients who underwent EBRT were deemed non-operable candidates due to severe comorbidities or advanced disease. Thus, definitive EBRT appears to be a viable treatment option for patients with LS-SCBC. We recognize that our cohort size and high censoring rate preclude a definitive comparison of the survival outcomes between patient cohorts. However, our experience is one of the larger, contemporary single-institution series reported to date and is consistent with other groups who observed similar patient outcomes between definitive treatment modalities $[12,13]$.
The SEER and NCDB databases have also been queried to assess the relative efficacy of RC and EBRT [2-4]. An initial study of SEER data from 1991-2005 included over 100 patients who received chemoradiation or surgery [4]. Outcomes following chemoradiation or cystectomy were similar. In an analysis from the NCDB of 625 patients with LSSCBC diagnosed between 1998-2010, the 3-year OS rate was most favorable in those undergoing neoadjuvant chemotherapy plus cystectomy $(53 \%)$ or chemoradiation (38\%) compared with single modality strategies [2]. An NCDB analysis including data from 2004-2013 also reported similar outcomes following surgery or radiation, with a median OS 32.4 and 34.1 months, respectively [3]. Our findings add to this body of literature, which suggests similar cure rates result from either EBRT or RC use in patients with LS-SCBC. 
Table 3

Selected case series reporting outcomes for LS-SCBC

\begin{tabular}{|c|c|c|c|c|c|c|c|c|}
\hline Institution & $\begin{array}{c}\text { Treatment } \\
\text { Period }\end{array}$ & $\begin{array}{c}\mathrm{N}+\text { or } \mathrm{M} 1 \\
(\%)\end{array}$ & $\begin{array}{l}\leq \mathrm{T} 2 \\
(\%)\end{array}$ & $\begin{array}{l}\text { EBRT } \\
(n)\end{array}$ & $\begin{array}{l}\mathrm{RC} \\
(\mathrm{n})\end{array}$ & $\begin{array}{l}\text { CTX } \\
(\%)\end{array}$ & OS & RFS/DFS \\
\hline $\begin{array}{l}\text { Univ. So. } \\
\text { California }[6]^{\dagger}\end{array}$ & 1971-2004 & 76 & 16 & - & 25 & 56 & $\begin{array}{l}\text { Median: } 13 \mathrm{~m} \\
5 \mathrm{yr}: 10 \%\end{array}$ & 5 yr: $13 \%$ \\
\hline Mayo Clinic [8] & $1975-2003$ & 34.2 & 16.1 & - & $38^{\ddagger}$ & 36.8 & Median: $1.7 \mathrm{yr}$ & \\
\hline Mayo Clinic [14] & 1980-2005 & 35.2 & 16.2 & - & 68 & 29.4 & $5 \mathrm{yr}: 30.3 \%$ & \\
\hline MD Anderson & 1985-2010 & & & & & & Median: & \\
\hline [13] & & $\begin{array}{l}0 \\
0\end{array}$ & 52 & $\begin{array}{l}12 \\
-\end{array}$ & $\frac{-}{95}$ & $\begin{array}{c}50 \\
72.6\end{array}$ & $\begin{array}{l}29.2 \mathrm{~m}(\text { EBRT }) \\
18.3 \mathrm{~m}(\mathrm{RC}) \\
159.5 \mathrm{~m} \\
(\mathrm{RC}+\mathrm{Neo}-\mathrm{CTX})\end{array}$ & \\
\hline $\begin{array}{l}\text { Rare Cancer } \\
\text { Network [12] }\end{array}$ & 1984-2012 & 14.4 & NR & 23 & $54^{\mathbb{I}}$ & $\sim 60$ & $\begin{array}{l}2 \mathrm{yr}: \\
36 \%(\mathrm{~N} 0) \\
24 \%(\mathrm{~N} 1+)\end{array}$ & $\begin{array}{l}2 \mathrm{yr}: \\
30 \%(\mathrm{~N} 0) \\
15 \%(\mathrm{~N} 1+)\end{array}$ \\
\hline NCI-AVL [27] & 1993-2016 & 24.6 & 77 & 65 & - & 100 & Median: $52 \mathrm{~m}$ & Median: $22 \mathrm{~m}$ \\
\hline
\end{tabular}

${ }^{\dagger}$ Includes 5 pts with large cell neuroendocrine. ${ }^{\ddagger} 3$ patients also received neoadjuvant radiation. Includes 37 tumors that were retrospectively re-classified as SCBC. ${ }^{I} 7$ patients also received peri-operative radiation. CTX: chemotherapy; NR: not reported; OS: overall survival; RFS: relapse free survival; DFS: disease free survival; RC: radical cystectomy; EBRT: external beam radiotherapy; NCI-AVL: Netherlands Cancer Institute-Antoni van Leeuwenhoek Hospital.

Our results are similar to previously published case series, though direct comparisons are limited by study population differences (Table 3). A trend, however, is observed with earlier studies reporting higher rates of node positive disease, lower rates of neoadjuvant chemotherapy utilization, and worse overall outcomes $[6,8,14]$. Major changes or advances have occurred during this time frame in supportive care, chemotherapeutic agents, surgical and radiation technology, and imaging quality which could also explain these improvements.

Prophylactic cranial irradiation (PCI) for patients with SCBC is of uncertain benefit. The procedure is associated with significant acute and long-term toxicities, including cognitive function decline during the first year after treatment, though modern techniques may decrease cognitive morbidity $[15,16]$. In patients with SCLC, where the incidence of brain metastasis (BM) approaches $60 \%$, PCI results in 50\% fewer BM and improves survival [17]. A meta-analysis of retrospective studies found that only $10.5 \%$ of all patients with SCBC develop BM, with more recent case series suggesting even lower incidence [12, 18, 19]. Patients with stage III-IV disease may have a higher incidence of BM, reported as high as 50\% in one small trial [20]. In our cohort, subsequent BM occurred in only three patients $(10 \%)$, and was the initial site of relapse in only one (3\%). Given the relatively low frequency of $\mathrm{BM}$ in ours and other case series, we do not advocate for routine PCI for patients with SCBC.

Many [2-4, 6, 13, 20, 21], but not all [12, 19], observational series have reported a survival advantage associated with the receipt of chemotherapy.
Our cohort further supports the use of chemotherapy in LS-SCBC: $84 \%$ of patients received systemic chemotherapy which was associated with improved MFS. These findings should be interpreted cautiously, however, given the wide confidence intervals and likely uncontrolled confounding variables such as the impact of patient fitness on eligibility for chemotherapy. In the only prospective clinical trial of chemotherapy for SCBC, eighteen patients with bladder-confined SCBC received neoadjuvant alternating doublet chemotherapy with etoposide-cisplatin and ifosfamide-doxorubicin prior to cystectomy [20]. Pathologic downstaging to $\leq \mathrm{pT} 1$ occurred in $78 \%$ of patients and the median OS was an impressive 58 months. A similar alternating, alkylator-based chemotherapy strategy was also studied in SCLC but has not been adopted clinically due to a lack of incremental benefit and high toxicity compared with cisplatin-etoposide alone [22]. Furthermore, ours and another contemporary series have observed high rates of pathologic downstaging with traditional platinum-based doublets approaching $50 \%$ [19]. Thus, we favor the combination of platinum plus etoposide without alternating ifosfamide and doxorubicin, but acknowledge that comparison is limited due to extrapolation from the SCLC literature.

No biomarkers have been identified to guide patient selection or to individualize treatment decisions for SCBC. Efforts to define genomic aberrations that occur in SCBC have identified potential therapeutic targets, though studies are limited by small sample size. Mutations in genes involved with DNA repair (eg. BRCA1/2, ERCC2) may be present in up 
to $26 \%$ of SCBCs and may predict for sensitivity to platinum-based chemotherapy based on observations from other tumor types [23, 24]. Pathogenic and potentially targetable mutations involving $E G F R$, ERBB2, MET, and PIK3CA have been detected at very low frequencies, while activating mutations in FGFR 1-3 are variably reported in $0-13 \%$ of cases [24-26]. Further studies of targeted agents are warranted, though are unlikely to benefit the majority of patients with SCBC. Improved patient selection, biomarkers, and therapeutic options are greatly needed for this rare disease.

In conclusion, patients with LS-SCBC in a modern cohort treated with either RC or EBRT had similar outcomes, though small cohort size limits firm conclusions regarding comparative efficacy of treatment modalities. Incorporation of chemotherapy, primarily platinum-based doublets, in a multimodality approach was associated with prolonged MFS only, but larger sample sizes are needed for more robust comparative analyses. These results support the notion that LS-SCBC is a systemic disease, and optimal management requires systemic therapy regardless of the modality selected for local disease control. PCI may not provide significant benefit for patients with LS-SCBC due to lower rates of brain metastases than small cell lung cancer.

\section{ACKNOWLEDGMENTS}

The authors have no acknowledgments.

\section{FUNDING}

This work was supported by The Leon and Sandra Levine Foundation and the 5MPOWER Foundation.

\section{AUTHOR CONTRIBUTIONS}

CMG contributed to the conception, writing, investigation, data collection/curation, formal analysis and project administration; DB contributed to the formal analysis and writing; CL contributed to methodology and investigation; JS contributed to formal analysis, supervision and resources; DRM contributed to writing and data curation; SR contributed to review/edit and investigation; PEC contributed to review/edit; HB contributed to writing; DR contributed to review/edit and supervision; EFB contributed to conception, methodology, writing, supervision and data collection/curation.

\section{CONFLICT OF INTEREST}

CMG has performed consulting/advisory roles for Tempus, EMD Serono, and Pfizer and received travel accommodations from Pfizer, Calithera Biosciences.

SR has ownership interests in Titan Medical and Rom Tech and a consulting/advisory role for CSATS.

EFB has ownership interests in Exelixis, Becton Dickinson, Calithera Biosciences, Gilead Sciences, Medtronic, Clovis Oncology; received honoraria from Exelixis, Bayer; had consulting/advisory roles for Johnson \& Johnson; speaker's bureau for Exelixis and Janssen; received research funding from Pfizer and Astellas Pharma; and received travel accommodations from Exelixis and Roche/Genentech.

DB, CL, JS, DRM, PEC, HB, and DR have no disclosures.

\section{REFERENCES}

[1] Koay EJ, Teh BS, Paulino AC, Butler EB. A Surveillance, Epidemiology, and End Results analysis of small cell carcinoma of the bladder: epidemiology, prognostic variables, and treatment trends. Cancer. 2011;117(23): 5325-33.

[2] Patel SG, Stimson CJ, Zaid HB, Resnick MJ, Cookson MS, Barocas DA, et al. Locoregional Small Cell Carcinoma of the Bladder: Clinical Characteristics and Treatment Patterns. J Urol. 2014;191(2):329-34.

[3] Fischer-Valuck BW, Rao YJ, Henke LE, Rudra S, Hui C, Baumann BC, et al. Treatment Patterns and Survival Outcomes for Patients with Small Cell Carcinoma of the Bladder. Eur Urol Focus. 2018;4(6):900-6.

[4] Koay EJ, Teh BS, Paulino AC, Butler EB. Treatment trends and outcomes of small-cell carcinoma of the bladder. Int J Radiat Oncol Biol Phys. 2012;83(1):64-70.

[5] Siefker-Radtke AO, Dinney CP, Abrahams NA, Moran C, Shen Y, Pisters LL, et al. Evidence supporting preoperative chemotherapy for small cell carcinoma of the bladder: a retrospective review of the M. D. Anderson cancer experience. J Urol. 2004;172(2):481-4.

[6] Quek ML, Nichols PW, Yamzon J, Daneshmand S, Miranda G, Cai J, et al. Radical cystectomy for primary neuroendocrine tumors of the bladder: the University of Southern California experience. J Urol. 2005;174(1):93-6.

[7] Bex A, Nieuwenhuijzen JA, Kerst M, Pos F, van Boven $\mathrm{H}$, Meinhardt W, et al. Small cell carcinoma of bladder: a single-center prospective study of 25 cases treated in analogy to small cell lung cancer. Urology. 2005;65(2):295-9.

[8] Choong NW, Quevedo JF, Kaur JS. Small cell carcinoma of the urinary bladder. The Mayo Clinic experience. Cancer. 2005;103(6):1172-8.

[9] Trias I, Algaba F, Condom E, Espanol I, Segui J, Orsola I, et al. Small cell carcinoma of the urinary bladder. Presentation of 23 cases and review of 134 published cases. Eur Urol. 2001;39(1):85-90.

[10] The World Health Organization histological typing of lung tumours. Second edition. Am J Clin Pathol. 1982;77(2):12336. 
[11] Detterbeck FC, Lewis SZ, Diekemper R, Addrizzo-Harris D, Alberts WM. Executive Summary: Diagnosis and management of lung cancer, 3rd ed: American College of Chest Physicians evidence-based clinical practice guidelines. Chest. 2013;143(5 Suppl):7s-37s.

[12] Pasquier D, Barney B, Sundar S, Poortmans P, Villa S, Nasrallah $\mathrm{H}$, et al. Small Cell Carcinoma of the Urinary Bladder: A Retrospective, Multicenter Rare Cancer Network Study of 107 Patients. Int J Radiat Oncol Biol Phys. 2015;92(4): 904-10.

[13] Lynch SP, Shen Y, Kamat A, Grossman HB, Shah JB, Millikan RE, et al. Neoadjuvant chemotherapy in small cell urothelial cancer improves pathologic downstaging and long-term outcomes: results from a retrospective study at the MD Anderson Cancer Center. Eur Urol. 2013;64(2): 307-13.

[14] Kaushik D, Frank I, Boorjian SA, Cheville JC, Eisenberg MS, Thapa P, et al. Long-term results of radical cystectomy and role of adjuvant chemotherapy for small cell carcinoma of the bladder. Int J Urol. 2015;22(6):549-54.

[15] Slotman BJ, Mauer ME, Bottomley A, Faivre-Finn C, Kramer GW, Rankin EM, et al. Prophylactic cranial irradiation in extensive disease small-cell lung cancer: short-term health-related quality of life and patient reported symptoms: results of an international Phase III randomized controlled trial by the EORTC Radiation Oncology and Lung Cancer Groups. J Clin Oncol. 2009;27(1):78-84.

[16] Gondi V, Paulus R, Bruner DW, Meyers CA, Gore EM, Wolfson A, et al. Decline in tested and self-reported cognitive functioning after prophylactic cranial irradiation for lung cancer: pooled secondary analysis of Radiation Therapy Oncology Group randomized trials 0212 and 0214 . Int J Radiat Oncol Biol Phys. 2013;86(4):656-64.

[17] Auperin A, Arriagada R, Pignon JP, Le Pechoux C, Gregor A, Stephens RJ, et al. Prophylactic cranial irradiation for patients with small-cell lung cancer in complete remission. Prophylactic Cranial Irradiation Overview Collaborative Group. N Engl J Med. 1999;341(7):476-84.

[18] Bex A, Sonke GS, Pos FJ, Brandsma D, Kerst JM, Horenblas S. Symptomatic brain metastases from small-cell carcinoma of the urinary bladder: The Netherlands Cancer Institute experience and literature review. Ann Oncol. 2010;21(11):2240-5
[19] Jung K, Ghatalia P, Litwin S, Horwitz EM, Uzzo RG, Greenberg RE, et al. Small-Cell Carcinoma of the Bladder: 20-Year Single-Institution Retrospective Review. Clin Genitourin Cancer. 2017;15(3):e337-e43.

[20] Siefker-Radtke AO, Kamat AM, Grossman HB, Williams DL, Qiao W, Thall PF, et al. Phase II Clinical Trial of Neoadjuvant Alternating Doublet Chemotherapy With Ifosfamide/Doxorubicin and Etoposide/Cisplatin in Small-Cell Urothelial Cancer. J Clin Oncol. 2009;27(16):2592-7.

[21] Mattes MD, Kan CC, Dalbagni G, Zelefsky MJ, Kollmeier MA. External beam radiation therapy for small cell carcinoma of the urinary bladder. Pract Radiat Oncol. 2015; 5(1):e17-22.

[22] Fukuoka M, Furuse K, Saijo N, Nishiwaki Y, Ikegami H, Tamura T, et al. Randomized trial of cyclophosphamide, doxorubicin, and vincristine versus cisplatin and etoposide versus alternation of these regimens in small-cell lung cancer. J Natl Cancer Inst. 1991;83(12):855-61.

[23] Teo MY, Bambury RM, Zabor EC, Jordan E, Al-Ahmadie $\mathrm{H}$, Boyd ME, et al. DNA Damage Response and Repair Gene Alterations Are Associated with Improved Survival in Patients with Platinum-Treated Advanced Urothelial Carcinoma. Clin Cancer Res. 2017;23(14):3610.

[24] Teo M, Hao X, Desai N, Ostrovnaya I, Arora A, Funt S, et al. Small cell carcinoma of the bladder (SCCB): Clinical, histopathologic, and genomic predictors of clinical outcomes. J Clin Oncol. 2017;35(6_suppl):294.

[25] Dawson NA, Geynisman DM, Burgess EF, Somer BG, Arguello D, Hauke RJ, et al. Molecular profiles of small cell bladder and prostate cancer and comparisons with small cell lung cancer. J Clin Oncol. 2018;36(6_suppl):264.

[26] Pal SK, Hoffman-Censits J, Elvin JA, Vergilio J, Suh J, Ramkisson S, et al. Comprehensive genomic profiling of relapsed and refractory small cell neuroendocrine carcinoma of the urinary bladder. J Clin Oncol. 2017;35:suppl $6 \mathrm{~S}$; abstract 350 .

[27] van de Kamp M, Meijer R, Pos F, Kerst M, van Werkhoven E, van Rhijn B, et al. Intravesical recurrence after bladder sparing treatment of small cell carcinoma of the bladder: Characteristics, treatment, and outcome. Urol Oncol. 2018;36(6):307 e1-e8. 